Pak. j. sci. ind. res. Ser. A: phys. sci. 2020 63A(3) 188-200

\title{
Exploring the Relationship Between Land Surface Temperature and Land Use Change in Lahore Using Landsat Data
}

\author{
Muhammad Nasar-u-Minallah \\ Department of Geography, Govt. Postgraduate College Gojra, Punjab, Pakistan \\ (received February 26, 2019; revised August 16, 2019; accepted August 21, 2019)
}

\begin{abstract}
The present study focuses on determining the correlation of land surface temperature (LST) with normalized difference builtup index (NDBI) and normalized difference vegetation index (NDVI) of Lahore, a metropolitan city of Pakistan using landsat 5 and 8 dataset. This study also categorizes different types of land use through supervised image classification scheme and maximum likelihood algorithm (MLA), and assess the correlation between LST and land use type of different classes. The results of the study indicate that modifications in type of land use altered spatial variations of land surface temperature in 1990 and 2015. The findings also show that the ever increasing temperature caused by impervious surfaces such as builtup area, roads, construction sites and vacant land considerably contributes to heat island effect. However, vegetation cover, green and blue spaces decrease LST and effectively relieve the effect of heat island. LST builds a strong positive correlation with NDBI and strong negative correlation with NDVI. Based on the regression analysis between LST and NDBI and NDVI, these indices can be utilized as a sign to assess the impact of LU changes on temperature. The results further indicates that LST changes follow the pattern of LU changes in Lahore and the warmness intensity has been observed highest in the high density builtup area and vacant land, while low at the green and blue spaces. The analysis reveals that an increase in LST by $1.98^{\circ} \mathrm{C}$ during the period of 25 years at the rate of $0.079{ }^{\circ} \mathrm{C} /$ year in high density builtup area was due to the excessive increase in settlement growth. The study concludes that change of land use has an effect on the LST in Lahore.
\end{abstract}

Keywords: land surface temperature, NDVI, NDBI, land use (LU), Lahore

\section{Introduction}

Urban heat island refers to the phenomenon of higher air and land surface temperatures in Urban areas as compared to the neighbouring country side (Sanecharoen et al., 2019; Guha et al., 2018). Land surface temperature is a significant parameter in exploring the energy balance and exchange of surface matter that control the surface's biological, chemical and physical processes on the Earth (Deng et al., 2018; Nasar-u-Minallah, 2018; Pu et al., 2006). It is extensively used in hydrology, biology, geochemistry and soil (Hao et al., 2016; Tomlinson et al., 2011). Land use change (LUC) is a significant factor that influences land surface temperature of an area (Deng et al., 2018). The roughness and surface reflectance of different types of land use are different, thus leading toward variances in land surface temperature (Hou et al., 2010). Furthermore, in the perspective of urbanization and growing associated human activities, the natural cover is transformed into impervious structure and the land surface is rapidly changing due to urban expansion (Li et al., 2017). The urban heat islands of large cities gradually increased since the last

Author for correspondance; E-mail: Nasarbhalli@gmail.com few decades (Guha et al., 2018; Stone, 2007) with the concentrations of human population in Urban areas, observed changes in regional land surface temperature were modelled globally (Chen et al., 2014; Georgescu et al., 2011; He et al., 2007). The correlation between urban heat islands and pattern of landscape is being considered globally (Du et al., 2016; Peng et al., 2016). Therefore, the quantitative correlation between LST and LU change must be explored in order to further evaluate the ecological effect of LST and to address regional environmental problems (Deng et al., 2018). Several studies find out that vacant land and builtup area accelerate LST intensity and UHI effects, whereas blue and green spaces decrease LST and the intensity of UHI effects on environment (Song et al., 2014; Amiri et al., 2009). Vegetation can effectually impact LST by regulating latent and sensible heat exchange and reflecting solar radiation and absorbing energy (Yuan et al., 2017). The energy balance and surface temperature of an area is greatly affected by vegetation cover, which affects the surface and air interchange of water and energy (Hao et al., 2016; Kumar and Shekhar, 2015). Moreover, LST is precise by the configuration and landscape composition complex pattern (Qian et al., 
2001). A number of scholars have established that socioeconomic and natural factors (Buyantuyev and $\mathrm{Wu}$, 2010), at the same time generate definite impacts on LST spatiotemporal pattern (Kuang et al., 2015; Jenerette et al., 2007).

Landsat 5 and 8, thermal infrared bands imagery, having a spatial resolution of $120 \mathrm{~m}$ and $100 \mathrm{~m}$, respectively, have been extensively used for local level measurement of LST (Wang et al., 2018; Bendib et al., 2017; Li et al., 2016; Chen et al., 2002). A number of LST retrieval algorithms have been established from Landsat data (Weng et al., 2004), such as algorithm of singlechannel (Jimenez-Munoz et al., 2009; Jimenez-Munoz and Sobrino, 2003) and algorithm of mono-window (Qin et al., 2001). By utilizing air and surface temperature and content of water vapour rather than atmospheric profiles, algorithm of mono-window can enhance LST measurement from Landsat data with only one thermal infrared band (Windahl and Beurs, 2016; Sobrino et al., 2004). The algorithm of split-window investigated by (Rozenstein et al., 2014; Li et al., 2013), in LST retrieval by considering landsat 8 two thermal infrared bands. Jimenez-Munoz et al. (2014) compared the splitwindow and single channel algorithm in LST reversal, and they established the correctness of the split window procedure marginally improved than the mono window algorithm in relationship with higher contents of water vapour. Hence, some short comings and problems found in the previous studies are quiet necessary to be addressed in the present study. Several investigation procedures, for instance directly through brightness surface temperature (Cai et al., 2011) have been employed to govern LST, thus decreasing accuracy of data.

A lager number of studies in different periods of time have been conducted to assess a relationship between LST and different LU indices for different type of study regions (Makinde and Agbor, 2019; Deilemai and Kamruzzaman, 2017; Estoque et al., 2017; Tran et al., 2017; Mushore et al., 2017; Mathew et al., 2016; Ma et al., 2010). But variations in land surface temperature associated with land use indices for large cities or for a small urban heat island zone within the boundary of a city. Land use changes have been considered the key drivers of environmental modification, and they can be influenced by microclimate variability and change (Shumilo et al., 2019; Stroppiana et al., 2014; Brunsell, 2006). Furthermore, Land surface temperature variations have been established both temporally and spatially through land use change (Pielke et al., 1998). The LST obtained through satellite borne instruments has been utilized in several studies of heat-balance to observe global climatic change (Bhattacharya et al., 2010) and to model urban climate (Fall et al., 2010). Planck's law of black body is utilized for computing brightness values of surface temperature as of the atmospheric radiances acquired from TIR bands of Landsat data (Friedl, 2002). Brightness values of surface temperature, are transformed into land surface temperature through surface emissivity value of land surface with respect to water content of the soil, roughness, vegetation density and ground surface thermal properties (Dash et al., 2002; Qin et al., 2001). As significant indicators of different types of land use (builtup, bare and vegetation) are such indices as NDBI, NDVI, RVI and SAVI (Yue et al., 2007), which have been extensively utilized to explore the correlation between vegetation density, builtup area and LST (Wei and Zhou, 2011; Julien et al., 2006). As the relationship of NDVI \& LST, ex-aggerated by numerous causes, is relatively multifarious (Zhou et al., 2011), thus it is essential to further evaluate the correlation of NDVI and LST (Deng et al., 2018; Ghobadi et al., 2015). Such studies have revealed strong quantitative relationship between temperature and land use (Cheng et al., 2008). The specific objectives of this study are: (1). To estimate LST from Landsat 5 and 8 thermal infrared bands for making a Spatiotemporal distribution maps of LST for Lahore (2) To correlate LST with NDBI and NDVI of Lahore (3) To recognize the land use change for 1990 and 2015 (4) To evaluate the LST of different type of land use (5) To explore the relationship between LST and LU.

Study area. Lahore is a cultural, commercial and academic center of Pakistan and it is the second largest city of the country in terms of population about 11 million (GOP, 2017) and an administrative capital of the Punjab province of Pakistan. Lahore, extends between $31^{\circ} 15^{\prime}-31^{\circ} 43^{\prime} \mathrm{N}$ and $74^{\circ} 10^{\prime}-74^{\circ} 39^{\prime} \mathrm{E}$, covers an area of $1,772 \mathrm{Km}^{2}$ (GOP, 2000) (Fig. 1). The average altitude is about 150 to $200 \mathrm{~m}$ above sea level. Lahore has extreme weather condition during both summer and winter. The summer season continues from April-September and May-June are considered the warmest months. The average maximum and minimum temperature of these months touches $40.4{ }^{\circ} \mathrm{C}$ and 27.3 ${ }^{\circ} \mathrm{C}$ respectively (GOP, 2000). Winter period persists from November to March, where December and January reflect the coldest months, during which the average temperature of maximum and minimum are $21.1^{\circ} \mathrm{C}$ and $7.2^{\circ} \mathrm{C}$ respectively (GOP, 2000). 


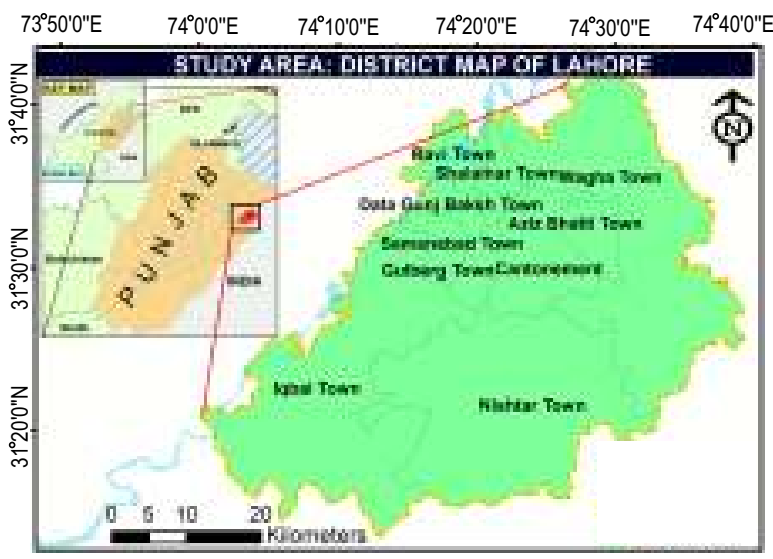

LEGEND

Caver Ravi

$\square$ Labore Distact

alabere Town

Fig. 1. Location of the study area.

According to the provisional census report, Lahore population is $11,126,285$ in 2017 (GoP, 2017). The alarming population growth rate of district Lahore has increased the population density from 640 in 1951 to 6,278 persons per $\mathrm{Km}^{2}$ in 2017 (GoP, 2017). According to the 2016 population estimates, Lahore district has 82.4 percent (GoP, 2016) urban population which has been increased to $100 \%$ in census of 2017 , in which whole district Lahore has been considered an urbanized area (GoP, 2017).

Lahore has recorded significant urban growth, expansion, development and infrastructural activities such as housing societies, commercial centers, buildings, road networks, deforestation and several anthropogenic activities in recent years with conversions of pervious surfaces to impervious surfaces and these changes have influenced the urban micro climate of Lahore. The rapid growth of urban population and urban expansion have significant environmental consequences for the future of sustainable cities in Pakistan.

\section{Material and Methods}

Data. Landsat 5 TM and Landsat 8 OLI _TIRS data of 16 March 1990 and 21 March 2015 respectively, for Lahore Fig. 2(a) and (b), displays the false colour composite image of Lahore which was utilized to calculate the LST and to sense the land use change and UHI. The digital data sets used in the present study were created by the USGS and were acquired in GeoTIFF. The satellite data description of Landsat 5 TM and $8 \mathrm{OLI}$ TIRS as well as their spectral and spatial characteristic is presented in Table 1. Landsat $5 \mathrm{TM}$ has one thermal band (6), whereas Landsat 8 TIRS dataset has two thermal bands of 10 and 11 .

The optical bands of satellite Landsat 5 and 8 were utilized in developing NBDI and NDVI. Imagery used for analysis is cloud free over Lahore and the quality of image is worthy and Level $1 \mathrm{~T}$, data product having geometrically corrected based on terrain, can be utilized directly. Landsat imageries were geo-referenced to the UTM projection system (WGS 1984, Zone 43N) and
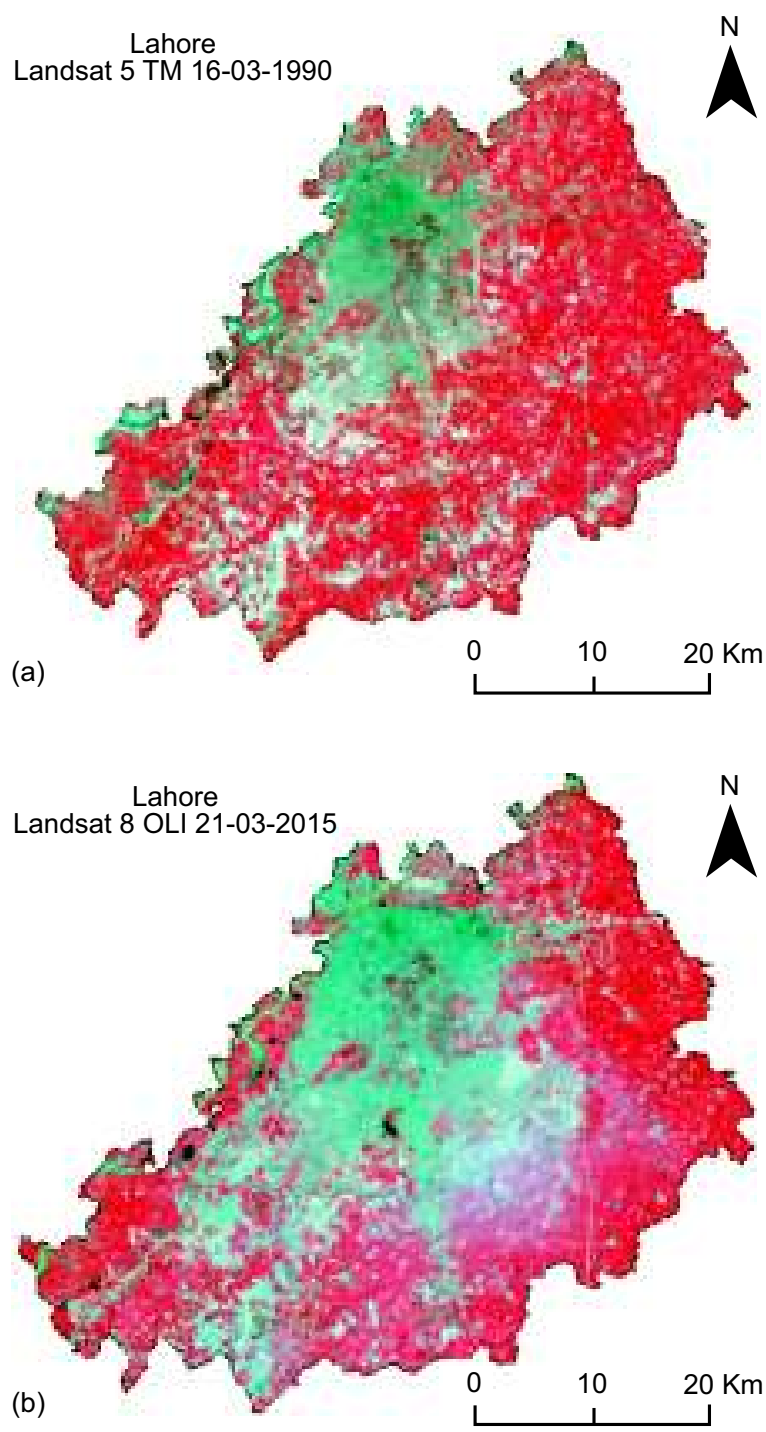

Fig. 2. Satellite images of Lahore: (a) FCC image of Landsat 5 TM 1990 (b) FCC image of Landsat 8 OLI 2015. 
Table 1. Landsat 5 and 8 data specification for Lahore

\begin{tabular}{|c|c|c|c|c|c|c|c|c|c|}
\hline $\begin{array}{l}\text { Date of } \\
\text { acquisition }\end{array}$ & Satellite & Sensor & Bands & $\begin{array}{l}\text { Spatial } \\
\text { resolution }\end{array}$ & $\begin{array}{l}\text { Thermal } \\
\text { resolution }\end{array}$ & Path/Row & Time & $\begin{array}{l}\text { Sun } \\
\text { elevation }\left(^{\circ}\right)\end{array}$ & $\begin{array}{l}\text { Cloud } \\
\text { cover }(\%)\end{array}$ \\
\hline \multirow[t]{2}{*}{$16 / 03 / 1990$} & Landsat 5 & $\mathrm{TM}$ & $1-5 \& 7$ & $60 \mathrm{~m}$ & - & $149 / 38$ & 04:57:07 & 43.41 & 1 \\
\hline & & & 6 & - & $120 \mathrm{~m}$ & & & & \\
\hline \multirow[t]{3}{*}{$21 / 03 / 2015$} & Landsat 8 & OLI & $1-8$ & $30 \mathrm{~m}$ & - & $149 / 38$ & 05:36:09 & 51.33 & 1.18 \\
\hline & & & Pan 9 & $15 \mathrm{~m}$ & - & & & & \\
\hline & & TIRs & $10 \& 11$ & - & $100 \mathrm{~m}$ & & & & \\
\hline
\end{tabular}

Source: http://earthexplorer.usgs.gov/

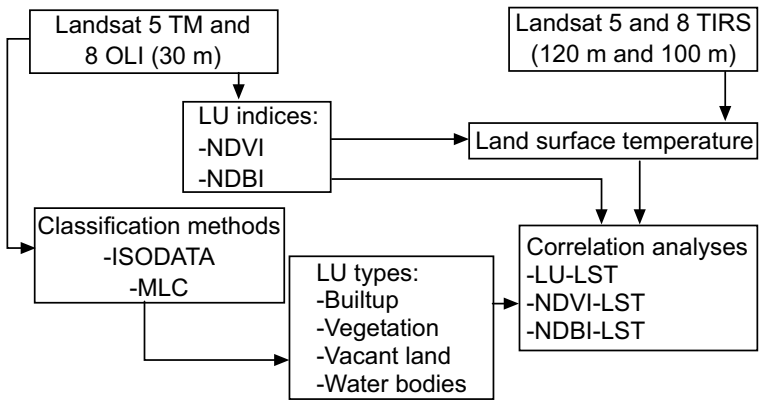

Fig. 3. Describes the flowchart of overall methodology of the present study.

the nearest-neighbor algorithm was used for resampling with size of pixel of $30 \mathrm{~m} * 30 \mathrm{~m}$. High resolution image of google earth was utilized to identify and detect land use change, as the reference data. Remote sensing and GIS software, ERDAS Imagine and ArcGIS were used to analyze the satellite data and acquire the concluding product during the whole study.

Pre-processing. The satellite images dataset obtained from the Landsat 5 and 8 were subset to the study area (Lahore) from the complete scene. The satellite imageries were first geo-referenced on a common coordinate system, UTM projection zone 43 and WGS84 datum and then geometrically and radio-metrically rectified to improve the image quality. The Landsat $5 \mathrm{TM}$ imagery thermal infrared band 6 has a spatial resolution of $120 \mathrm{~m}$, while Landsat 8 TIRS image thermal infrared band (10 and 11) has a spatial resolution of $100 \mathrm{~m}$. These two thermal infrared bands (6 and 10) were resampled to match the optical bands by using the algorithm of nearest neighbor with a size of pixel is $30 \mathrm{~m}$. In order to analyze the changes in land use (LU) and LST distribution patterns in the study area, the NDBI and NDVI indices were useful for determining the relationship with resultant land surface temperature.
Land use classification. The NDVI (Purevdorj et al., 1998) utilized in this study is extensively used to detect vegetation cover. On the contrary NDBI (Chen et al., 2006; Zha et al., 2003) was used to extract builtup area. The above mentioned indices can also be used to classify different land use types through the values of suitable threshold (Chen et al., 2006). Image classification is a method whereby all the pixels of image are classified into different type of land use classes and theme (Lillesand et al., 2000). Land use classification scheme utilized in this research adopts to classification procedure level I as given by Anderson, (1976). A total number of four land use classes were generated including builtup, vegetation, vacant land and water bodies. Landsat data was employed to carry out classification through the supervised image classification system, and maximum likelihood algorithm was used to acquire a batter result in order to extract builtup area and vacant land. The overall accuracy and kappa coefficient values were computed as 0.88 and 0.79 respectively for Landsat 5 and 91.46 and 85.23 respectively for Landsat 8 .

Retrieving brightness temperature. The following process was carried out to retrieve the land brightness temperature, as given by Joshi and Bhatt (2012) and Hashim et al. (2007). Digital number (DN) to spectral radiance $\left(\mathrm{L}_{\lambda}\right)$ conversion for Landsat $5 \mathrm{TM}$ is calculated through the equation 1 given by Irish (2000).

$$
\mathrm{L}_{\lambda}=1.238+(15.60-1.238) * \mathrm{DN} / 255
$$

The spectral radiance $\left(\mathrm{L}_{\lambda}\right)$ for Landsat 8 TIRS is calculated by using the equation 2 given by Zanter (2016).

$$
\mathrm{L}_{\lambda}=0.0003342 * \mathrm{DN}+0.1
$$

where:

$\mathrm{L}_{\lambda}$ is designated the spectral radiance.

$$
\mathrm{T}_{\mathrm{B}}=\mathrm{K}_{2} / \ln \left(\mathrm{K}_{1} / \mathrm{L}_{\lambda}+1\right)-273
$$


where:

$\mathrm{T}_{\mathrm{B}}$ is defined as brightness temperature in degree Celsius $\left({ }^{\circ} \mathrm{C}\right)$, while $\mathrm{K}_{2}$ and $\mathrm{K}_{1}$ are calibration constants. The value of $K_{1}$ is 607.76 , and the value of $K_{2}$ is 1260.56 for Landsat 5 TM, and for Landsat 8 TIRS band 10, the value of $K_{1}$ and $K_{2}$ is 775.89 and 1321.08 , respectively (Nasar-u-Minallah, 2019).

Calculation of NDVI. The below equation 4 is utilized to calculate NDVI given by Gao, (1996) and Purevdorj et al., (1998).

$$
\mathrm{NDVI}=\mathrm{R}_{\mathrm{NIR}}-\mathrm{R}_{\text {red }} / \mathrm{RNIR}+\mathrm{R}_{\text {red }}
$$

Land surface emissivity. In this study, the process of determining emissivity value from NDVI is specified by Sobrino et al., (2004 and 2008) has been useful.

$$
\varepsilon=\left[\begin{array}{ll}
0.979-0.035 \mathrm{P}_{\mathrm{V}} & \mathrm{NDVI}<0.2 \\
0.986+0.004 \mathrm{P}_{\mathrm{V}} & 0.2<\mathrm{NDVI}<0.5 \\
.99 & \mathrm{NDVI}>0.5
\end{array}\right.
$$

Under this method, according to the values of NDVI, the pixels were divided into 3 categories. If the values of NDVI exceeds 0.5 , the pixels of the image are supposed to be covered completely by vegetation. In such cases, the emissivity $(\varepsilon)$ values are equal to 0.99 and assigned them. On the other hand, if the values of NDVI pixels range from $0.2-0.5$, the value of proportional vegetation $\left(\mathrm{P}_{\mathrm{V}}\right)$ is calculated through below equation 5 (Nasar-u-Minallah, 2019).

$$
\begin{aligned}
& \mathrm{P}_{\mathrm{V}}=\left[\left(\mathrm{NDVI}-\mathrm{NDVI}_{\min }\right) /\right. \\
& \left.\left(\mathrm{NDVI}_{\max }-\mathrm{NDVI}_{\min }\right)\right]^{2} \ldots
\end{aligned}
$$

Finally the emissivity $(\varepsilon)$ value was attained from simple linear regression, using the $\mathrm{P}_{\mathrm{V}}$ values of equation 5 and appraisal the values of emissivity $(\varepsilon)$ through below equation 6 .

$$
\operatorname{LSE}(\varepsilon)=0.004 * \mathrm{P}_{\mathrm{V}}+0.986
$$

Retrieval of land surface temperature (LST). If the emissivity values are known, LST can be calculated though equation 7 .

$$
\mathrm{LST}=\left(\mathrm{T}_{\mathrm{B}} / 1+\lambda *\left(\mathrm{~T}_{\mathrm{B}} / \rho\right) * \ln (\varepsilon)\right)
$$

where:

$\lambda$ denoted the effective wavelength for Landsat 8 thermal band 10 is $10.9 \mathrm{~mm}$ (Guha et al., 2018) and the value of $\rho$ is 14380 and $\varepsilon$ is emissivity.

Derivation of NDBI. The following equation 8 was used to compute NDBI given by Zha et al. (2003) and Chen et al. (2006).

$$
\begin{aligned}
& \mathrm{NDBI}=\mathrm{NDBI}=(\mathrm{SWIR}-\mathrm{NIR}) / \\
& (\mathrm{SWIR}+\mathrm{NIR}) \ldots \ldots \ldots \ldots \ldots \ldots \ldots \ldots \ldots \ldots \ldots \ldots \ldots
\end{aligned}
$$

Regression analysis. This study through linear regression analysis determine the correlation of LST, NDVI, NDBI and land use for a period of 25 years. NDVI and NDBI are considered independent variables, while LST is a dependent variable. The linear regression equation is given by Seber (2012), as below:

$$
\mathrm{Y}=\alpha+\beta \mathrm{X}
$$

To observe the correlation between NDVI, NDBI and LST, random sample point sites were chosen by using Feature Class "Create Random Point Tool" for each NDBI, NDVI and LST image and then by using 'Extract Multi values to point' tool in ArcGIS to get values of NDBI, NDVI, and LST (Nasar-u-Minallah, 2017).

\section{Results and Discussion}

Spatio-temporal distribution of LST, NDBI \& NDVI. The descriptive statistics of LST, NDBI and NDVI of Lahore are presented in Table 2 for the year 1990 and 2015. Land surface temperature distribution was classified into high and low temperature range (Fig. 4), and thermal pattern distribution maps of LST of Lahore are generate through appropriate color symbology. The values of mean LST for Lahore are $21.83^{\circ} \mathrm{C}$ and 25.4 ${ }^{\circ} \mathrm{C}$ for 1990 and 2015, respectively. The mean value of NDBI of Lahore is -0.20 for the year 1990, while for 2015 is -0.26 and 2015 . The mean value of NDVI of Lahore for the year 1990 is 0.29 while for 2015 is 0.27 .

Relationship between land use (LU) and LST. The relationship between LST and LU has revealed a positive correlation. The characteristics of the correlation between surface temperature and LU are brief in Table 3. Fig. 5 shows mean LST by different types of LU in the study area. It is an interesting fact that distribution of land surface temperature is closely associated with NDBI and NDVI distribution. NDBI and NDVI are two land use indices heavily dependent on the different forms of land use in any region. Typically, high values of NDBI reflect the existence of built-up area and vacant land, while high values of NDVI show the abundance of vegetation and green spaces. Fundamentally, with an increase in builtup area, the LST of an area also increases, whereas it decreases with the increase of green and blue spaces.

Figure 5 also describe the different types of land use change of Lahore for the year 1990 and 2015 with the 

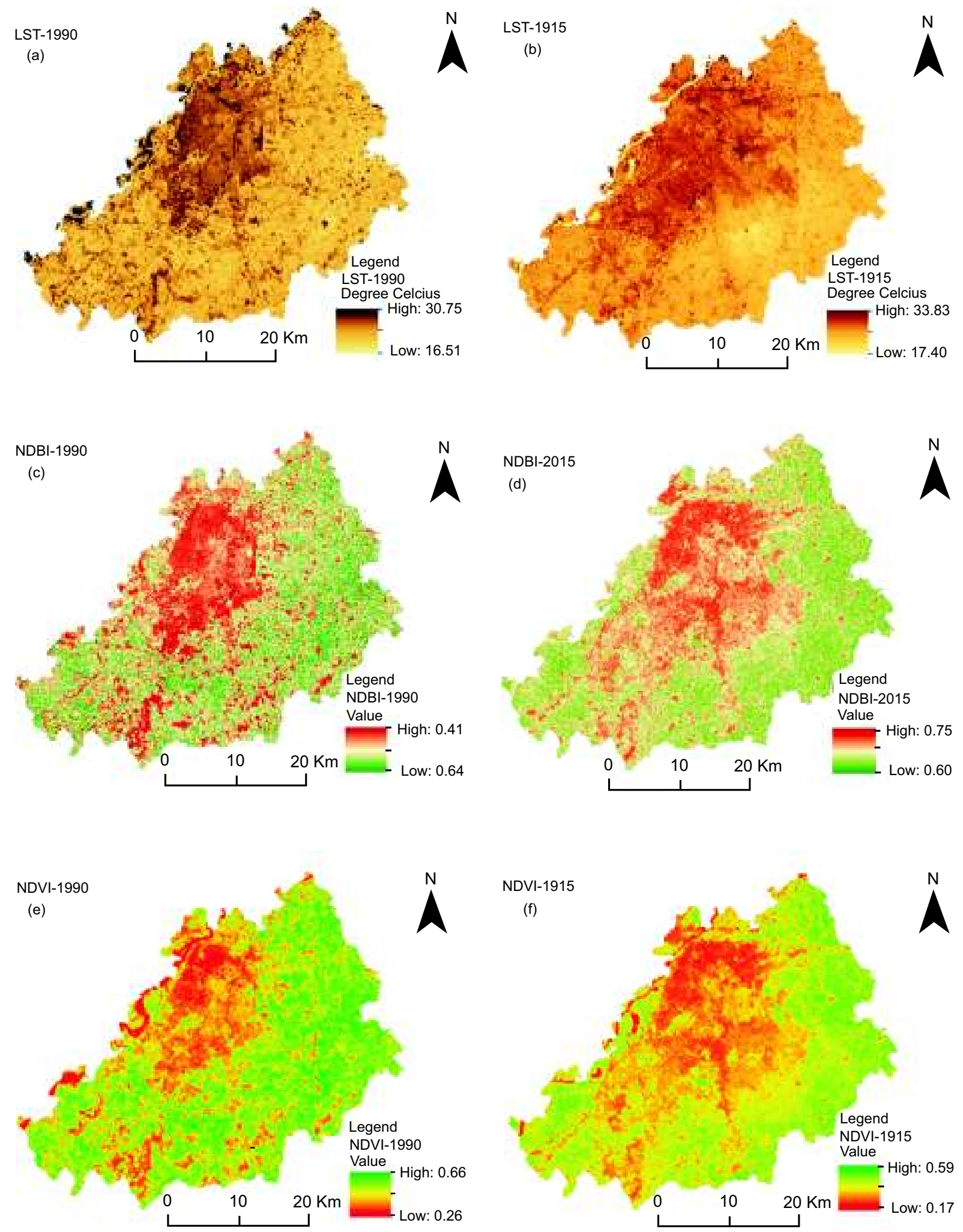

Fig. 4. Spatio-temporal distribution Map of LST: (a) 1990 and (b) 2015; NDBI: (a) 1990 and (b) 2015; NDVI: (a) 1990 and (b) 2015. 
Table 2. Descriptive statistics of LST, NDBI and NDVI of Lahore

\begin{tabular}{|c|c|c|c|c|c|c|c|c|c|c|c|c|}
\hline \multirow[t]{2}{*}{ Year } & \multicolumn{4}{|c|}{$\operatorname{LST}\left({ }^{\circ} \mathrm{C}\right)$} & \multicolumn{4}{|c|}{ NDBI } & \multicolumn{4}{|c|}{ NDVI } \\
\hline & Min & Max & Mean & SD & Min & Max & Mean & SD & Min & Max & Mean & SD \\
\hline 1990 & 16.51 & 30.75 & 21.83 & 1.39 & -0.64 & 0.41 & -0.20 & 0.16 & -0.26 & 0.66 & 0.29 & 0.19 \\
\hline 2015 & 17.40 & 33.83 & 25.4 & 1.36 & -0.60 & 0.75 & -0.26 & 0.14 & -0.17 & 0.59 & 0.27 & 0.13 \\
\hline
\end{tabular}

Max: maximum; Min: minimum; SD: standard deviation (Nasar-u-Minallah, 2017).

support of optical bands of Landsat satellite data, Google earth image and LU indices. In 1990 the builtup area of district Lahore was $352.75 \mathrm{~km}^{2}$ but builtup area increased to $643.51 \mathrm{~km}^{2}$ in 2015 , whereas vegetation
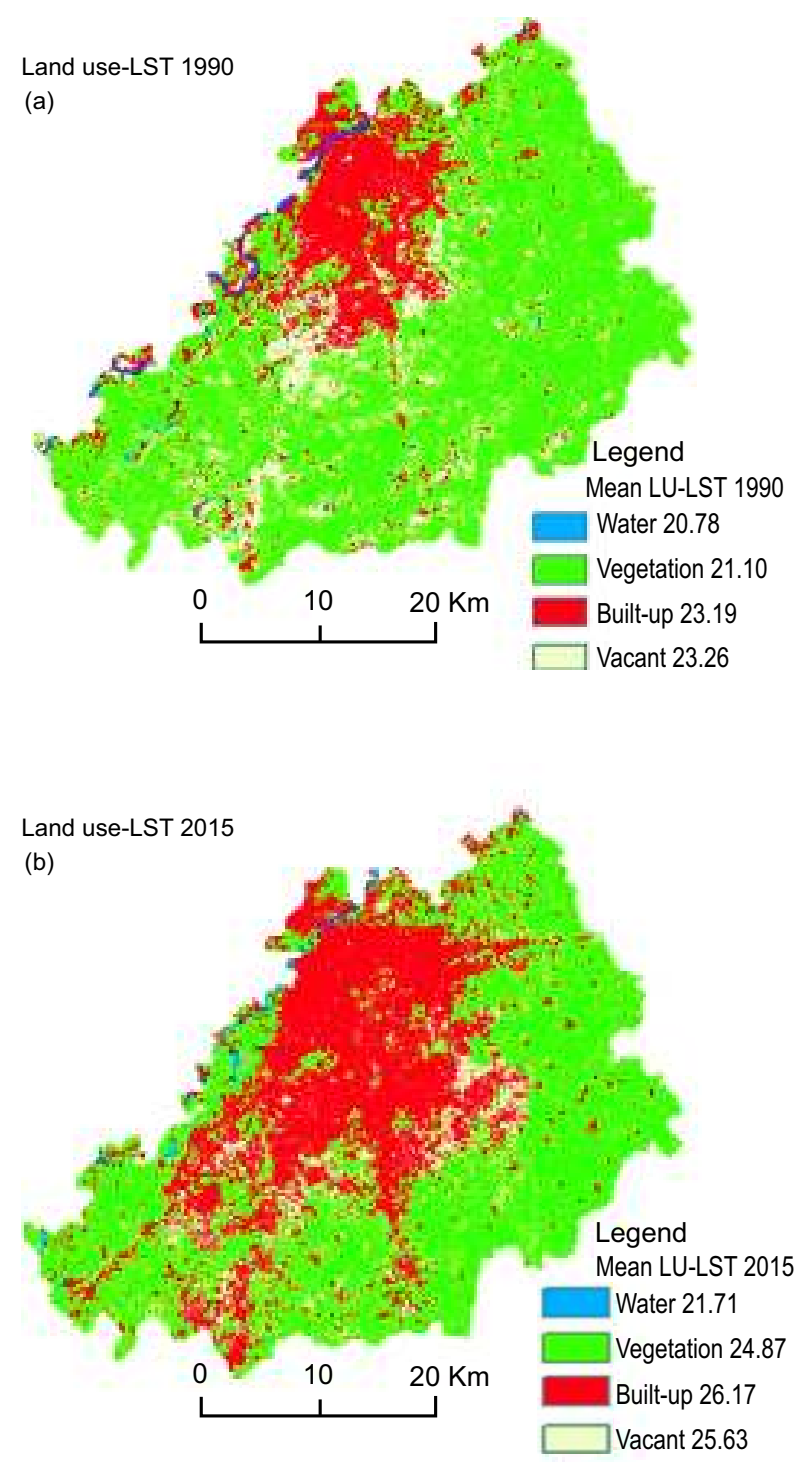

Fig. 5. LST change with different types of Land use: (a) 1990; (b) 2015. cover in 1990 is $1117.82 \mathrm{~km}^{2}$ in 1990 , it decreased to $915.71 \mathrm{~km}^{2}$ in 2015 . The rapid increase of LST over the years of study can be attributed to the rapidly urbanizing the city has witnessed. It is obvious from the Fig. 5 that the densely populated, builtup, commercial and industrial areas in the city have higher surface temperature due to more impervious surfaces. These impervious surface absorbed and store heat during day time while release heat during night time that is a contributing factor to increase LST in urban areas as compared to rural areas.

A cross comparison between the LST-LU map (Fig. 5) reflects a minimum temperature of about $20^{\circ} \mathrm{C}-21^{\circ} \mathrm{C}$ in water bodies and a maximum temperature of $23^{\circ} \mathrm{C}$ $-26{ }^{\circ} \mathrm{C}$ in builtup area while areas under vegetation cover had moderation temperature. It reflects that the urban expansion is contributing to increase land surface temperature by replacing the green spaces with nonevaporating, non-transpiring surfaces of asphalt, concrete, stone and metal. In contrast to that, the land under the use of green spaces and agricultural land for growing crops in neighboring countryside's have lower surface temperature as compared to the city environment.

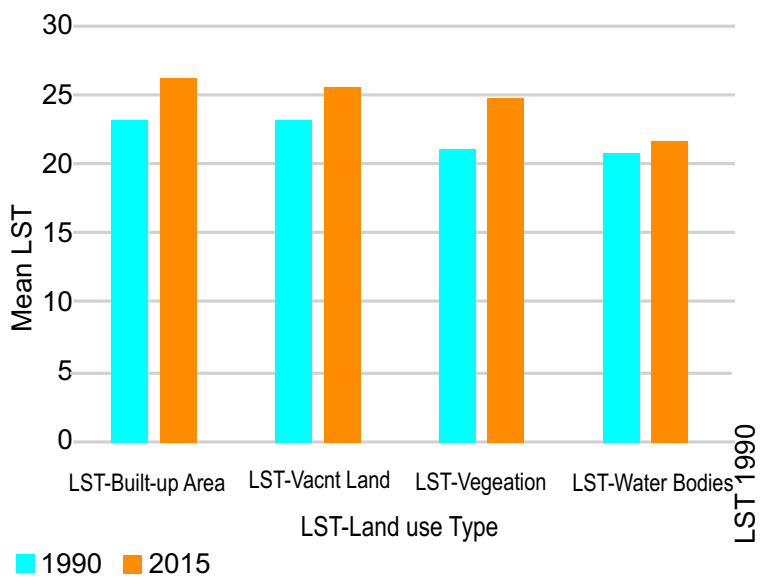

Fig. 6. LST variations with different type of Land use in 1990 and 2015. 
Table 3. LST variations with different type of Land use

\begin{tabular}{|c|c|c|c|c|c|c|c|c|c|c|c|c|}
\hline \multirow[t]{2}{*}{ Year } & \multicolumn{3}{|c|}{ LST- Built-up area } & \multicolumn{3}{|c|}{ LST- Vacant land } & \multicolumn{3}{|c|}{ LST- Vegetation } & \multicolumn{3}{|c|}{ LST-Water bodies } \\
\hline & Min. & Max. & Mean & Min. & Max. & Mean & Min. & Max. & Mean & Min. & Max & Mean \\
\hline 1990 & 18.78 & 29.11 & 23.19 & 19.68 & 30.75 & 23.16 & 18.78 & 27.03 & 21.10 & 16.51 & 28.28 & 20.78 \\
\hline 2015 & 17.86 & 33.84 & 26.17 & 17.41 & 33.27 & 25.63 & 19.12 & 31.60 & 24.87 & 19.13 & 28.47 & 21.71 \\
\hline
\end{tabular}

It is apparent that from Table 3 and Fig. 5 shows that the builtup area revealed the highest mean surface temperature that is $23.19^{\circ} \mathrm{C}$ in 1990 and $26.17^{\circ} \mathrm{C}$ in 2015 , while vacant land mean surface temperature is $23.16^{\circ} \mathrm{C}$ in 1990 and $25.63{ }^{\circ} \mathrm{C}$ in 2015 . This highlights that the urbanization and urban growth is associated with the increasing LST by changing natural surfaces into urban structure i.e., non-transpiring, non-evaporating surfaces such as impervious surface (concrete, asphalt, stone and metal). Lower temperature was observed at water bodies and blue spaces $\left(19-21^{\circ} \mathrm{C}\right)$ as compared to other LU classes, followed by the vegetation (21-24 ${ }^{\circ} \mathrm{C}$ ). Henceforth, the blue and green spaces have cooler effect as compared to built-up area and vacant land.
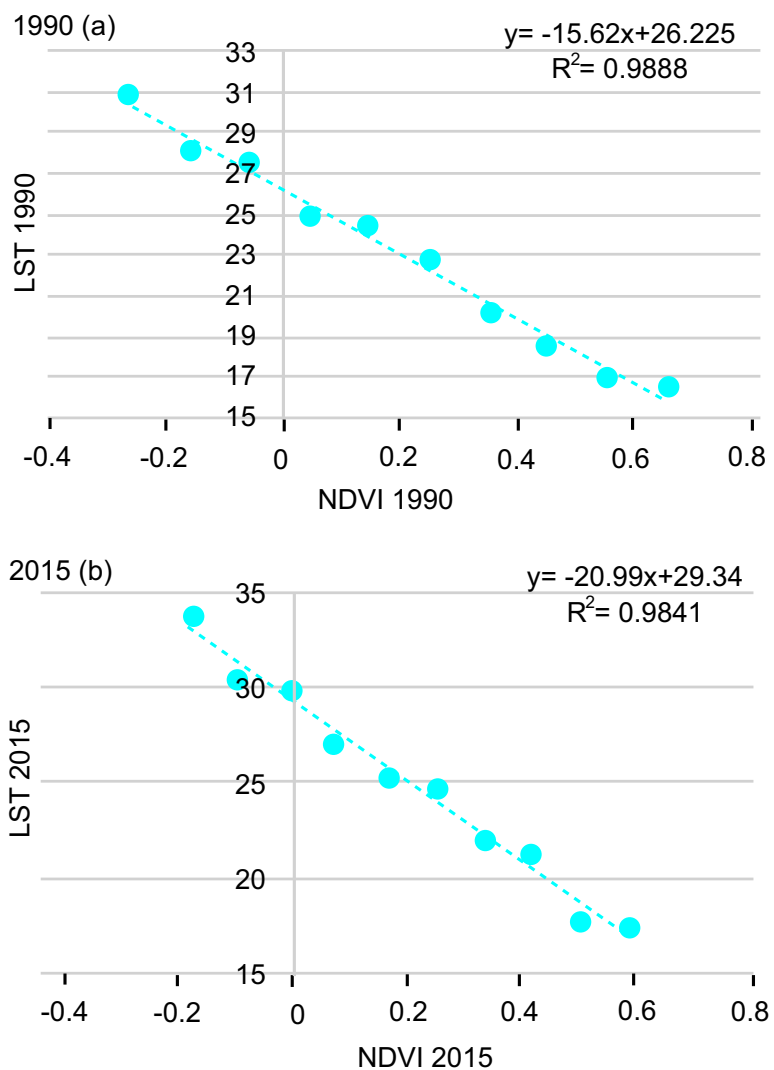

Fig. 7. Relationship between NDVI and LST: (a) 1990 and (b) 2015.
Relationship between NDVI, NDBI and LST. The relationship between the NDBI, NDVI and LST is valued for the understanding of urban microclimate. In general, LST offers a negative correlation with NDVI, whereas positive correlation with NDBI. In the present study, NDVI displays very strong negative correlation with LST of Lahore -0.98 for the year (1990) and (2015) as shown in Fig. 7(a) and (b), whereas NDBI reflects a highly positive correlation with LST of Lahore 0.98 for the year (1990) and (2015) as shown in Fig. 8(a) and (b). The city of Lahore supports the common correlation of LST with NDBI and NDVI. It is detected that the values of NDVI reduced from 1990-2015 due to the expansion of builtup area and decrease of
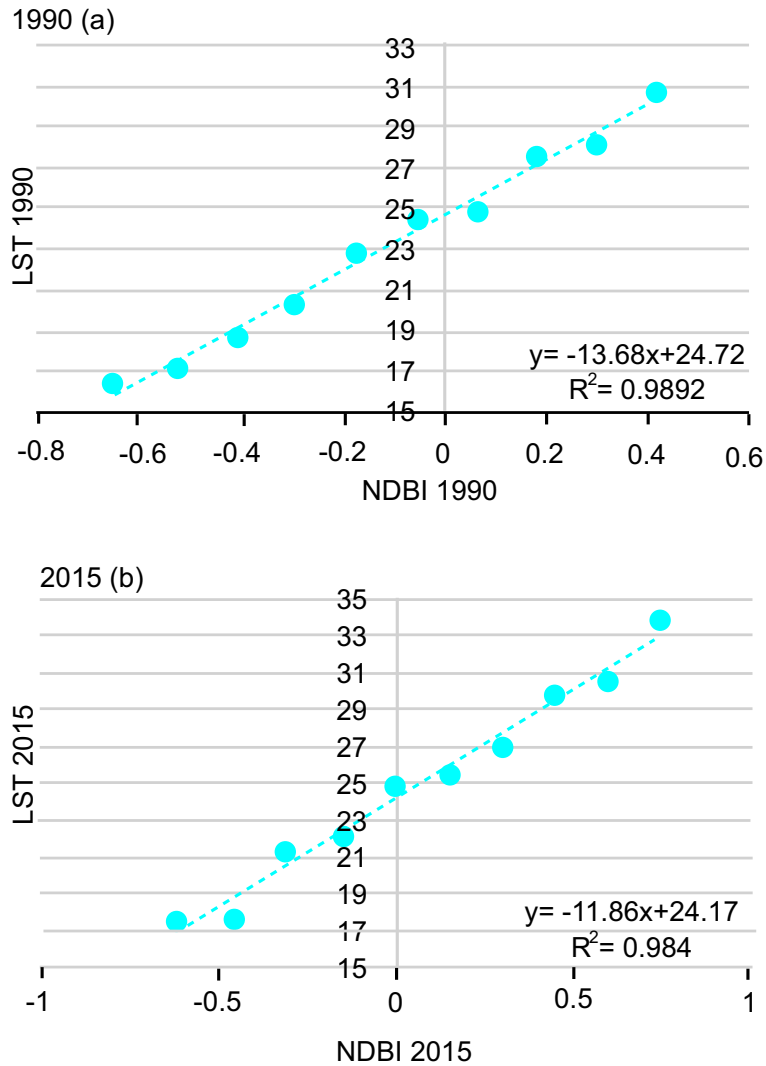

Fig. 8. Relationship between NDBI and LST; (a) 1990 and (b) 2015. 
vegetation and urban green spaces in city of Lahore. Spatial pattern of NDVI distribution is not only be influenced by reduced urban green spaces, but it can also be attributed to topography, availability of solar radiation and other factors.

Figure $7(a)$ and (b) reflects a very strong negative correlation between LST and NDVI. The vegetation index (NDVI) served as an indicator of vegetation abundance in an area, the areas with the dense vegetation cover exhibited lowest surface temperature as the area under vegetation cover and urban green spaces determines the LST through the process of evapotranspiration from surface to atmosphere by latent heat flux. The vegetation cover and urban green spaces add moisture in the atmosphere and decrease the effect of heat in the urban environment. The highest values of NDVI were observed in the south and southeast as shown Fig. 4(e) and (f) where vegetation cover and cropland were mostly located in the city of Lahore. The lowest values of NDVI were recognized in the densely builtup residential areas, commercial and industrial areas with less vegetation cover (Fig. $4 \mathrm{e}$ and $\mathrm{f}$ ). It also indicates that the areas exhibiting lowest values of NDVI have less vegetation and urban green spaces as a consequence of urbanization and urban development, whereas the higher values of NDVI have dense vegetation cover, and therefore, surface temperature increases with the decrease in density of vegetation cover. In case of Lahore, a strong relationship is observed between NDVI and LST, which ensures the prospect of using linear regression in predicting accurate LST if the values of NDVI are known. Fig. 7(a) and (b) also indicate high values of NDVI had low LST, while the regions with lowest values of NDVI had higher land surface temperature. It is also seen (Fig. 4e and f) that the values of NDVI decreased from 1990-2015 due to urbanization and urban development which has led to massive reduction in urban green spaces and vegetation cover.

Figure 8(a) and (b) shows a very strong positive correlation between LST and NDBI. The builtup index (NDBI) is utilized to extract builtup area and strengthen builtup and bare land information. The relationship between NBDI and LST are directly proportional to each other, regions higher in LST had high density builtup area as compared to the regions with less builtup area with lower surface temperature. The urban growth and high density of builtup area is clearly reflected through normalized difference builtup index in Fig. 4(c) and (d).
It can also be seen in the analysis of 1990 and 2015 NDBI maps as presented in Fig. 4(c) and (d), that the highest values of NDBI were recognized in the core of the city, showed with purple colour. The areas with the highest values of NDBI were core city of Lahore, while the urban green space, vegetation and Ravi River had the lowest value of NDBI. The higher values of NDBI were found in the central area of Lahore, concentrated by concrete surfaces, parking lots, high building density and sky scrapers while the lower values of NDBI were observed in the east and southeast outskirts of Lahore as shown in Fig. 4(c) and (d) and the values of NDBI increased from 1990-2015 due to urbanization and developmental activities since 1980, which led to increase builtup area and impervious surfaces.

\section{Conclusion}

The findings of the study confirmed a negative correlation existed between LST and NDVI as previously comprehended from other studies and a positive relationship between LST and NDBI. It was also observed that LST was very sensitive to moisture content in the atmosphere as well as vegetation cover. LST was very closely linked to builtup and vacant land for the case of land use type. The results also point out that land use type has considerable impact on land surface temperature as estimated through the Landsat TM and OLI_TIRS imagery. The results illustrate that the urban temperature is influenced generally by the surface materials and has a close relationship to the abundance of vegetation. Areas of the highest LST were identified as the builtup, CBD, industrial, construction areas and vacant land, while the temperature was lower in the areas where blue and green spaces. The findings also exhibit a high correlation between LST and land use, therefore, enlightening different environmental factors attributed to urban expansion process in Lahore. Rapid urban expansion led to the replacement of natural surfaces to artificial surfaces in the form of road network, building and anthropogenic activities also transformed natural surfaces to impervious surfaces. The continuous and massive changes of land use with urban sprawl is causing the destruction of the ecosystem in urban green space which led to increase LST. The process of intensification of LST of Lahore is gradual but definite. In future, further research works may be included. First, based on this work, a recommendation for minimizing and reducing the UHII phenomena in inner city, urban fringe, and suburb areas of Lahore is to add more green 
spaces. Secondly, LST may be retrieved through another technique or different spatial resolution on metropolitan areas with the use of different satellite data such as MODIS, Sentinel and other satellite images are recommended. Thirdly, the in situ data may be recorded with the same overpass of satellites for the validation and calibration of LST assessment. Finally, ecological assessment of UHI zones may be studied in the addition to bio-physical parameters.

\section{References}

Anderson, J.R. 1976. A Land Use and Land Cover Classification System for Use with Remote Sensor Data (Vol. 964): US Government Printing Office, Washington DC., USA.

Amiri, R., Weng, Q., Alimohammadi, A., Alavipanah, S.K. 2009. Spatial-temporal dynamics of land surface temperature in relation to fractional vegetation cover and land use/cover in the Tabriz urban area, Iran. Remote Sensing of Environment, 113: 2606-2617.

Bendib, A., Dridi, H., Kalla, M.I. 2017. Contribution of landsat 8 data for the estimation of land surface temperature in Batna city, eastern Algeria. Geocarto International, 32: 503-513.

Bhattacharya, B., Mallick, K., Patel, N., Parihar, J. 2010. Regional clear sky evapotranspiration over agricultural land using remote sensing data from Indian geostationary meteorological satellite. Journal of Hydrology, 387: 65-80.

Brunsell, N. 2006. Characterization of land-surface precipitation feedback regimes with remote sensing. Remote Sensing of Environment, 100: 200-211.

Buyantuyev, A., Wu, J. 2010. Urban heat islands and landscape heterogeneity: linking spatiotemporal variations in surface temperatures to land-cover and socio-economic patterns. Landscape Ecology, 25: $17-33$.

Cai, H., Liu, P., Song, J., Zeng, Z. 2011. Study on retrieval of urban heat island effect from $\mathrm{RS}$ date in a typical karst area, a case study in Guiyang city. Earth and Environment, 39: 246-250.

Chen, A., Yao, X.A., Sun, R., Chen, L. 2014. Effect of urban green patterns on surface urban cool islands and its seasonal variations. Urban Forestry and Urban Greening, 13: 646-654.

Chen, X.L., Zhao, H.M., Li, P.X., Yin, Z.Y. 2006. Remote sensing image-based analysis of the relationship between urban heat island and land use/cover changes. Remote Sensing of Environment, 104: 133-146.

Chen, Y.H., Wang, J., Li, X.B. 2002. A study on urban thermal field in summer based on satellite remote sensing. Remote Sensing for Land and Resources, 14: $55-59$.

Cheng, K.S., Su, Y.F., Kuo, F.T., Hung, W.C., Chiang, J.L. 2008. Assessing the effect of land cover changes on air temperature using remote sensing imagesA pilot study in northern Taiwan. Landscape and Urban Planning, 86: 297-297.

Dash, P., Göttsche, F.M., Olesen, F.-S., Fischer, H. 2002. Land surface temperature and emissivity estimation from passive sensor data: theory and practice-current trends. International Journal of Remote Sensing, 23: 2563-2594.

Deng, Y., Wang, S., Bai, X., Tian, Y., Wu, L., Xiao, J., Qian, Q. 2018. Relationship among land surface temperature and LUCC, NDVI in typical karst area. Scientific Reports, 8: 641.

Deilami, K., Kamruzzaman, M. 2017. Modelling the urban heat island effect of smart growth policy scenarios in Brisbane. Land Use Policy, 64: 38-55.

Du, H., Wang, D., Wang, Y., Zhao, X., Qin, F., Jiang, H., Cai, Y. 2016. Influences of land cover types, meteorological conditions, anthropogenic heat and urban area on surface urban heat island in the Yangtze river delta urban agglomeration. Science of the Total Environment, 571: 461-470.

Estoque, R.C., Murayama, Y., Myint, S.W. 2017. Effects of landscape composition and pattern on land surface temperature: An urban heat island study in the megacities of southeast Asia. Science of the Total Environment, 577: 349-359.

Fall, S., Niyogi, D., Gluhovsky, A., Pielke Sr, R.A., Kalnay, E., Rochon, G. 2010. Impacts of land use land cover on temperature trends over the continental United States: assessment using the north American Regional Re-analysis. International Journal of Climatology, 30: 1980-1993.

Friedl, M. 2002. Forward and inverse modeling of land surface energy balance using surface temperature measurements. Remote Sensing of Environment, 79: 344-354.

Gao, B.C. 1996. NDWI-A normalized difference water index for remote sensing of vegetation liquid water from space. Remote Sensing of Environment, 58: 257-266. 
Georgescu, M., Moustaoui, M., Mahalov, A., Dudhia, J. 2011. An alternative explanation of the semiarid urban area "oasis effect". Journal of Geophysical Research: Atmospheres, 116:.

Ghobadi, Y., Pradhan, B., Shafri, H.Z.M., Kabiri, K. 2015. Assessment of spatial relationship between land surface temperature and land use/cover retrieval from multi-temporal remote sensing data in South Karkheh Sub-basin, Iran. Arabian Journal of Geosciences, 8: 525-537.

GOP, (Government of Pakistan). 2000. District Census Report of Lahore 1998. Islamabad: Population Census Organization, Statistics Division. Govt. of Pakistan.

GOP, (Government of Pakistan). 2017. Provisional Summery of Census 2017. Islamabad: Population Census Organization, Bureau of Statistics. Govt. of Pakistan.

GOP, (Government of Pakistan). 2016. Punjab Development Statistics 2016. Bureau of Statistics Lahore. Government of the Punjab. Pakistan.

Guha, S., Govil, H., Dey, A., Gill, N. 2018. Analytical study of land surface temperature with NDVI and NDBI using Landsat 8 OLI and TIRS data in Florence and Naples city, Italy. European Journal of Remote Sensing, 51: 667-678.

Hao, X., Li, W., Deng, H. 2016. The oasis effect and summer temperature rise in arid regions-case study in Tarim Basin. Scientific Reports, 6: 35418.

Hashim, N., Ahmad, A., Abdullah, M. 2007. Mapping urban heat island phenomenon, remote sensing approach. Journal of Institution of Engineers, Malaysia, 68: 25-30.

He, J., Liu, J., Zhuang, D., Zhang, W., Liu, M. 2007. Assessing the effect of land use/land cover change on the change of urban heat island intensity. Theoretical and Applied Climatology, 90: 217-226.

Hou, G., Zhang, H., Wang, Y., Qiao, Z., Zhang, Z. 2010. Retrieval and spatial distribution of land surface temperature in the middle part of Jilin province based on MODIS data. Scientia Geographica Sinica, 30: 421-427.

Irish, R.R. 2000. Landsat 7 science data users handbook. National Aeronautics and Space Administration, Report, 2000: 415-430.

Jenerette, G.D., Harlan, S.L., Brazel, A., Jones, N., Larsen, L., Stefanov, W.L. 2007. Regional relationships between surface temperature, vegetation and human settlement in a rapidly urbanizing ecosystem. Landscape Ecology, 22: 353-365.
Jiménez-Muñoz, J.C., Sobrino, J.A., Skokovic, D., Mattar, C., Cristóbal, J. 2014. Land surface temperature retrieval methods from Landsat- 8 thermal infrared sensor data. IEEE Geoscience and Remote Sensing Letters, 11: 1840-1843.

Jiménez-Muñoz, J.C., Cristóbal, J., Sobrino, J.A., Sòria, G., Ninyerola, M., Pons, X. 2009. Revision of the single-channel algorithm for land surface temperature retrieval from Landsat thermal-infrared data. IEEE Transactions on Geoscience and Remote Sensing, 47: 339-349.

Jiménez-Muñoz, J.C., Sobrino, J.A. 2003. A generalized single-channel method for retrieving land surface temperature from remote sensing data. Journal of Geophysical Research: Atmospheres, 108:

Joshi, J.P., Bhatt, B. 2012. Estimating temporal land surface temperature using remote sensing: A study of Vadodara urban area, Gujarat. International Journal of Geology, Earth and Environmental Sciences, 2: 123-130.

Julien, Y., Sobrino, J.A., Verhoef, W. 2006. Changes in land surface temperatures and NDVI values over Europe between 1982 and 1999. Remote Sensing of Environment, 103: 43-55.

Kuang, W., Liu, Y., Dou, Y., Chi, W., Chen, G., Gao, C., Zhang, R. 2015. What are hot and what are not in an urban landscape: quantifying and explaining the land surface temperature pattern in Beijing, China. Landscape Ecology, 30: 357-373.

Kumar, D., Shekhar, S. 2015. Statistical analysis of land surface temperature-vegetation indexes relationship through thermal remote sensing. Ecotoxicology and Environmental Safety, 121: 39-44.

Li, W., Cao, Q., Lang, K., Wu, J. 2017. Linking potential heat source and sink to urban heat island: Heterogeneous effects of landscape pattern on land surface temperature. Science of the Total Environment, 586: 457-465.

Li, Y., Zhu, L., Zhao, X., Li, S., Yan, Y. 2013. Urbanization impact on temperature change in China with emphasis on land cover change and human activity. Journal of Climate, 26: 8765-8780.

Li, Z., Duan, S., Tang, B., Wu, H., Ren, H., Yan, G., Leng, P. 2016. Review of methods for land surface temperature derived from thermal infrared remotely sensed data. Journal of Remote Sensing, 20: 899920.

Lillesand, T., Kiefer, R. 2000. Remote Sensing and Image Interpretation, 724 pp., Willey and Sons, New York, USA. 
Ma, Y., Kuang, Y., Huang, N. 2010. Coupling urbanization analyses for studying urban thermal environment and its interplay with biophysical parameters based on TM/ETM+ imagery. International Journal of Applied Earth Observation and Geo information, 12: 110-118.

Makinde, E., Agbor, C. 2019. Geoinformatic assessment of urban heat island and land use/cover processes: a case study from Akure. Environmental Earth Sciences, 78: 483.

Mathew, A., Sreekumar, S., Khandelwal, S., Kaul, N., Kumar, R. 2016. Prediction of surface temperatures for the assessment of urban heat island effect over Ahmedabad city using linear time series model. Energy and Buildings, 128: 605-616.

Mushore, T.D., Mutanga, O., Odindi, J., Dube, T. 2017. Assessing the potential of integrated landsat 8 thermal bands, with the traditional reflective bands and derived vegetation indices in classifying urban landscapes. Geocarto International, 32: 886-899.

Nasar-u-Minallah, M. 2019. Retrieval of land surface temperature of Lahore through landsat-8 TIRS data. International Journal of Economic and Environment Geology, 10: 70-77.

Nasar-u-Minallah, M. 2018. Spatial and temporal change assessment in land surface temperature of Lahore using GIS and remote sensing techniques. Proceedings of the Pakistan Academy of Sciences: Pakistan Academy of Sciences A. Physical and Computational Sciences, 55: 67-75.

Nasar-U-Minallah, M. 2017. Assessing the impact of urban expansion on land surface temperature in Lahore using remote sensing techniques. Unpublished Ph.D. Thesis, Department of Geography, University of the Punjab, Lahore, Pakistan.

Peng, J., Xie, P., Liu, Y., Ma, J. 2016. Urban thermal environment dynamics and associated landscape pattern factors: a case study in the Beijing metropolitan region. Remote Sensing of Environment, 173: $145-155$.

Pielke, R.A., Avissar, R., Raupach, M., Dolman, A.J., Zeng, X., Denning, A.S. 1998. Interactions between the atmosphere and terrestrial ecosystems: influence on weather and climate. Global Change Biology, 4: 461-475.

Pu, R., Gong, P., Michishita, R., Sasagawa, T. 2006. Assessment of multi-resolution and multi-sensor data for urban surface temperature retrieval. Remote Sensing of Environment, 104: 211-225.

Purevdorj, T., Tateishi, R., Ishiyama, T., Honda, Y.
1998. Relationships between percent vegetation cover and vegetation indices. International Journal of Remote Sensing, 19: 3519-3535.

Qin, Z., Karnieli, A., Berliner, P. 2001. A mono-window algorithm for retrieving land surface temperature from Landsat TM data and its application to the Israel-Egypt border region. International Journal of Remote Sensing, 22: 3719-3746.

Rozenstein, O., Qin, Z., Derimian, Y., Karnieli, A. 2014. Derivation of land surface temperature for landsat8 TIRS using a split window algorithm. Sensors, 14: 5768-5780.

Sanecharoen, W., Nakhapakorn, K., Mutchimwong, A., Jirakajohnkool, S., Onchang, R. 2019. Assessment of urban heat island patterns in Bangkok metropolitan area using Time-series of landsat termal ifrared data. Environment and Natural Resources Journal, 17: 87-102.

Seber, G.A.F., Lee, A.J. 2012. Linear Regression Analysis, $2^{\text {nd }}$ (eds.). vol. 329, John Wiley \& Sons,.

Shumilo, L., Yailymov, B., Kussul, N., Lavreniuk, M., Shelestov, A., Korsunska, Y. 2019. Rivne City Land Cover and Land Surface Temperature Analysis Using Remote Sensing Data. Paper Presented at the 2019 IEEE 39th International Conference on Electronics and Nanotechnology (ELNANO).

Sobrino, J.A., Jimenez-Munoz, J.C., Paolini, L. 2004. Land surface temperature retrieval from LANDSAT TM 5. Remote Sensing of Environment, 90: 434440.

Sobrino, J.A., Jiménez-Muñoz, J.C., Sòria, G., Romaguera, M., Guanter, L., Moreno, J., Martínez, P. 2008. Land surface emissivity retrieval from different VNIR and TIR sensors. IEEE Transactions on Geoscience and Remote Sensing, 46: 316-327.

Song, J., Du, S., Feng, X., Guo, L. 2014. The relationships between landscape compositions and land surface temperature: Quantifying their resolution sensitivity with spatial regression models. Landscape and Urban Planning, 123: 145-157.

Stone Jr, B. 2008. Urban sprawl and air quality in large US cities. Journal of Environmental Management, 86: 688-698.

Stroppiana, D., Antoninetti, M., Brivio, P.A. 2014. Seasonality of MODIS LST over Southern Italy and correlation with land cover, topography and solar radiation. European Journal of Remote Sensing, 47: 133-152.

Tomlinson, C.J., Chapman, L., Thornes, J.E., Baker, C. 2011. Remote sensing land surface temperature for 
meteorology and climatology: a review. Meteorological Applications, 18: 296-306.

Tran, D.X., Pla, F., Latorre-Carmona, P., Myint, S.W., Caetano, M., Kieu, H.V. 2017. Characterizing the relationship between land use land cover change and land surface temperature. ISPRS Journal of Photogrammetry and Remote Sensing, 124: 119132.

Wang, S., Ma, Q., Ding, H., Liang, H. 2018. Detection of urban expansion and land surface temperature change using multi-temporal Landsat images. Resources, Conservation and Recycling, 128: 526534.

Wei, M., Zhou, J. 2011. Quantitative analysis of land surface temperature--vegetation indexes relationship based on remote sensing. The International Archives of the Photogrammetry, Remote Sensing and Spatial Information Sciences, vol. XXXVII, part B6b. Beijing, 261-264.

Weng, Q., Yang, S. 2004. Managing the adverse thermal effects of urban development in a densely populated Chinese city. Journal of Environmental Management, 70: 145-156.

Windahl, E., de Beurs, K. 2016. An intercomparison of
Landsat land surface temperature retrieval methods under variable atmospheric conditions using in situ skin temperature. International Journal of Applied Earth Observation and Geoinformation, 51: 11-27. Yuan, X., Wang, W., Cui, J., Meng, F., Kurban, A., Maeyer, P. 2017. Scientific Reports, 7: 3287.

Yue, W., Xu, J., Tan, W., Xu, L. 2007. The relationship between land surface temperature and NDVI with remote sensing: application to Shanghai landsat 7 $\mathrm{ETM}+$ data. International Journal of Remote Sensing, 28: 3205-3226.

Zanter, K. 2016. Landsat 8 (L8) data users handbook. Landsat Science Official Website. Available online: https://landsat.USGS.Gov/landsat-8-l8-data-usershandbook (Accessed on 20 January 2018).

Zha, Y., Gao, J., Ni, S. 2003. Use of normalized difference builtup index in automatically mapping urban areas from TM imagery. International Journal of Remote Sensing, 24: 583-594.

Zhou, Y., Shi, T., Hu, Y., Liu, M. 2011. Relationships between land surface temperature and normalized difference vegetation index based on urban land use type. Chinese Journal of Ecology, 30: 15041512. 